\title{
Introduction: Analysis of Cultural Heritage
}

The following seven papers in this section are from the 9th Region Workshop of the European Microbeam Analysis Society (EMAS) on Electron Probe Analysis of Materials Today-Practical Aspects that took place April 25-28, 2010 in Amsterdam, The Netherlands. The meeting was organized in collaboration with the Netherlands Institute for Cultural Heritage (ICN).

The EMAS Regional Workshop is a biennial event designed to provide postgraduate students, researchers, and technicians in material science and engineering with basic knowledge of the capabilities and limitations of electron probe microanalysis (EPMA). The workshop is arranged as a low-cost meeting with lectures on practical and theoretical aspects of EPMA given by internationally recognized experts. The content of the meeting is tailored to the needs of the practical microanalyst routinely dealing with the problems of specimen preparation, instrument procedures, data collection and quantification, as well as the needs of researchers keen to deepen their understanding of the physics underlying X-ray production, measurement, and analysis. The workshop has a very distinct format comprising invited lectures, delivered by eminent scientists, poster presentations by the participants, and roundtable discussions on the key topics led by experts in the field. Previous workshops in the series were held in Finland (1994), Hungary (1996), Spain (1998), The Czech Republic (2000), Poland (2002), Slovenia (2004), Germany (2006), and Italy (2008).

Since at ICN X-ray microbeam analysis is applied to cultural heritage, such as paintings, ancient textiles, glass, pottery, and metal artifacts, the workshop incorporated two technical sessions dedicated to microbeam analysis in the cultural heritage field. For these two sessions EMAS and ICN invited speakers on the following topics: characterization of painting techniques by multispectral infrared (IR) reflectography, identification of pigments by scanning micro-X-ray fluorescence, the study of surfaces by low-voltage and variable pressure scanning electron microscopy, identification of early synthetic organic dyestuffs using $\mu$-Raman spectroscopy, the analysis of ancient and historic glass by inductively coupled plasma mass spectrometry, and in situ analysis of surfaces by portable X-ray diffraction and fluorescence. In addition, results of studies with newly developed noninvasive instruments such as the multispectral IR scanner and acoustic microscope were reported.

The Amsterdam workshop attracted 72 participants from 16 countries. There were 18 invited lectures, and 20 posters were displayed during the Workshop. The seven papers published in this issue of Microscopy and Microanalysis have been selected from the two sessions dedicated to microbeam analysis in the field of cultural heritage. All the papers have been subjected to the rigorous peer review procedure of Microscopy and Microanalysis.

Clive Walker

President of EMAS

Ineke Joosten

LOC Chair 